SF 995 .H65 Copy 1

\title{
THE
}

CHICKEN CHOLERA

Preventive and Exterminator

A TREATISE GIVING

The Cause, Symptoms, Prevention,

AND EXTERMINATION

OF

\section{CHICKEN CHOLERA}

By A. J. HILL,

BLRBANK. WAYNE COUNTY, OHIO.

Second Edilion.

WOOSTER :

Repubitcan Stream Press Print. 1875. 



\title{
THE
}

\section{CHICKEN CHOLERA}

\section{Preventive and Exterminator}

\author{
A TREATISE GIVING
}

The Cause, Symptoms, Prevention,

\author{
AND EXTERMINATION
}

OF

\section{CHICKEN CHOLERA}

\section{By A. J. HILL,}

BURBANK, WAYNE COUNTY, OHIO.

Second Edition.

WOOSTER : 0 .

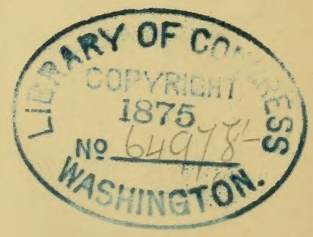

Republican Steam Press Print. 
Entered according to act of Congress, in the year 1875 , by

A. J. HILL,

In the Office of the Librarian of Congress, at Washington, D. C. 


\section{INTRODUCTION.}

dil

N placing this little work before the public, it is proper that a few statements be made by way of introduction. I have made cholera among fowls the subject of much study and investigation, and the conclusions reached are presented in this work.

We may hope to be successful in our efforts to prevent and cure this disease when we have correct and well defined ideas as to its cause. I have thought that this was a matter of considerable importance, for it is obvious that in proportion as we are able to trace this disease to its source, we may expect to prevent or extinguish its cause. From these considerations I have been particular to make the cause of the disease a subject of careful investigation.

The various subjects presented are arranged and divided so as to be easily comprehended, and convenient for reference.

It is believed that a work of this kind is needed-a work that is short and right to the point, and a work that is exclusively devoted to the subject of chicken cholera.

It is presumed that some mistakes have been made, but it is believed that they are of such a nature as not to essentially affect the value of the work.

I wish to acknowledge the favors that I have received from W. H. Todd, the veteran breeder, and Editor of the Poultry Nation. Knowing that I was preparing a work of this kind he has kindly given me much encouragement and advice. The work was pretty well advanced, yet some of his thoughts and 
ideas have been used. It is believed that poultry breeders will find it to their interest to give this work such favor as will bring it into general use.

Nearly every breeder in the country feels that cholera, and the fear of it, is an obstacle to the increase of the poultry inter. est, and that we need a treatise on that disease, that is more definite, and reliable, than anything that we now have. One of Mr. Todd's letters refers to this matter, and I will close my remarks and give an extract from his letter.

A. J. Hill, Burbank, Wayne Co., Ohio

"A treatise on cholera is very important, and in publishing your work you are on the right track. I have no doubt it will be of great value. I hope you will be able to give the public something valuable on cholera, for this scourge, and the dread of it, is a formidable barrier to the increase of the poultry interest, preventing many from keeping fowls who would otherwise enjoy it.

I would say search diligently and be as thorough as you can on the subject. No danger of too much being known on chol. era."

W. H. TODD.

Vermillion, Ohio. 


\section{Chicken Cholera,--Its Cause.}

(4)

HICKEN cholera is alarmingly on the increase in many discouragement to poultry breeders and others The cause of this disease should be ascertained if possible and removed, and then the effect will cease. The following pages will be exclu sively devoted to the subject of chicken cholera-its cause, symptoms, prevention, and extermination.

The limits of this work will not permit any extended argument on the question of its cause, but I claim to have sufficient evidence to warrant me in saying that it is local. Wherever the disease prevails, right there is where its cause exists; and there is the place where its cause was generated, unless infec. tious matter had been introduced by diseased fowls or otherwise.

Where a flock of fowls are exempt from this disease, it is because certain conditions that are necessary to the production of its cause, or to give it a favorable opportunity, to act do not exist.

A special cause is undoubtedly necessary to the production of this disease, but there are various agents and influences that act as co-operating causes. By removing as far as possible all co-operating causes, the special cause in most cases may be rendered to a great extent inoperative, for the co operating causes and the special cause of this disease are like the two 
blades of a pair of scissors-" conjoined they are effective, but disunited they effect nothing."

Fowls that are in a low, unthrifty condition are in just the right shape to be acted upon by the special cause of cholera; it is therefore proper to class all agents and influences that tend to produce that condition as co operating causes of that disease; and wherever cholera prevails, investigation will show that the special cause is, in most cases, aided by one or more of the co-operating causes.

\section{THE CO-OPERATING CAUSES OF, CHOLERA.}

As already stated, there are many conditions and influences that have an unfavorable influence on fowls, and they are classed as aiding causes of cholera; some of the prominent ones are as follows:-Want of sufficient shade in hot weather, exposure in cold weather, hen lice, drinking impure water, or a lack of a plenty of pure, cold water, or a lack of gravel and alkali, unwholesome food, keeping the fowls either too fat or too poor, or not giving them a sufficient variety of food, damp filthy and poorly ventilated yards and fowl houses, and want of sufficient sun-light in their rooms, and a lack of suffizient exercise from too close confinement.

But there is one fact that I wish to make prominent and it should be remembered; and that is, that the co-operating causes, singly, nor all together, are the real cause $r f$ chicken cholera. They are simply aids : and the part that they act is chiefly in putting the fowls in that condition where they can be effectively acted upon by the special cause of that disease. In most cases where the conditions are such that a considerable amount of the special cause has been produced, there will be a sufficient number of general causes ready to aid it, and unless means are used to destroy, or weaken the special cause, and to remove or lessen the aiding causes,cholera will be the result. 


\section{THE SPECIFIC CAUSE OF CHOLERA.}

The existence of one specific cause may be inferred from the specific and distinctive character of the disease; its phenomona is so distinctive, and so uniform that it must have a specific and uniform cause. The arguments of the highest authorities in medical science bring us to such a conclusion; and this conclusion has such an important bearing on the question under consideration that it should be emphasized; and with that object in view the statement will be varied a little and repeated-the pathology of this disease is so distinctive and specific that it cannot be produced by any general cause, nor by a variety of causes, nor by any combination of general causes. It must be produced invariably by one cause-a cause that is as specific and uniform as the disease that it produces. The cooperating causes have no influence whatever in giving the disease its distinctive character, for that is wholly derived from the peculiar nature of the specific cause.

Our knowledge of this invisible agent is limited, but from certain data we arrive at some pretty definite conclusions in regard to its nature, its source, and the modus operandi by which it gives rise to morbid manifestations.

The special poison that produces this disease is peculiar in its nature, and it differs very much from the miasm that produces cholera, in man. The latter is migratory in its nature, the former is not. The special cause of cholera in man is supposed to be produced in the place from which it takes its point of departure, and it is then transported from place to place through the atmosphere.

There is sufficient evidence to show that the poison that pro. duces chicken cholera is generated on the premises where the disease prevails, and that it remains mostly local unless carried abroad by other means than the atmosphere. 
Chicken cholera is contagious, Asiatic cholera is not. The two diseases are dissimilar in many other respects, but we omit any further comparison.

I have made the etiology of this disease among fowls the sub. ject of much study and research; I have studied it in all its bearings, and have investigated and experimented until certain conclusions have been reached, and it is believed they are based on reason and fact. I have some knowledge of general and special pathology, and it is my opinion that the character of this disease is nearly the same as typhus dysentery in men. They have a close resemblance to each other, and there is evidence to show that the specific cause of both diseases are gener. ated by the operation of the same law. For these reasons and others that have been given, I think that the name of chicken cholera is a misnomer.

The disease to which chicken cholera is so closely allied is infectious, and by that means, and by fomites, it may be diffused abroad; but otherwise it is not migratory, and its specific cause has a local origin. These peculiarities will apply to chicken cholera and its specific cause. It is not only contagious, but it is quite clear that damp grain and other food can be sufficiently infected to communicate the disease to fowls that should eat it; and if this food were completely infected and excluded from the air it might be carried for miles and fed to fowls with the same result.

In writing on typhus disease, a prominent medical author says: "Facts appear to render it highly probable that the disease is developed as a consequence of over-crowding and deficient ventilation; in other words, that the concentrated emanations from the bodies of healthy persons may suffice for the generating of typhus miasma."

He goes on to show that this poison, generated from the con. centrated emanations from human bodies, is the special cause 
of typhus disease in prisons, hospitals, work-houses, ships, unventilated tenement houses that are crowded with occupants, and in military camps.

When human habitations are poorly ventilated and overcrowded, diseases of various kinds will be the result of the unwholesome emanations; and when the emanations become sufficiently concentrated, the typhus poison will be generated. The virulence and fatality of the typhus disease that will follow, will be in proportion to the amount of poison present, and the influence of co-operating causes.

In my opinion this is a plain solution of the question under consideration-the cause of chicken cholera. If too many fowls are kept together, or if their is insufficient ventilation of their houses and yards, there will be an accumulation, and a concentration of the emanations from their bodies, which, when in a mild form, will be capable of prolucing many of the diseases that fowls are subject to. If a further concentration be permitted, the point will be reached when a new substance will be produced-a specific poison will be generated, and if aiding causes are favorable, cholera will be the result, and the elements of infection will be in active operation.

As has been stated, it is quite probable that this poison is produced, by the operation of some law of nature, from the con. centrated emanations from the bodies of the fowls; and the concentration is the result of over-crowding and insufficient ventilation. But there is no doubt that dampness, filth, and many other influences, often have much to do in making the conditions favorable for its generation.

After having been produced, this deleterious substance will quickly have its eflect on those fowls that are in a suitable con. dition to be acted upon; some will be able to resist its influences, or at least for a while; and so the disease will go on, 
rapid or slow, violent or mild, according to aiding influences and the amount of poison present.

Is is impossible to tell just how this specifi: acts in order to produce the varions phenomena of chicken cholera, but from the distinctive character of the lisease, we have a right to attribute it to a toxical origin.

Wherever cholera lrevails the conditions are such as to favor the production of the specific that has been referred to, and it is reasonable to suppose that it produces the disease.

The theory that has been alvanced will not suffer by being applied to any given case where fowls are kept, for it can easily be harmonized with anyexisting fart; at least the solution will be no more difficult than it often is in other cases of disease that have a recognized and specific origin

If the disease prevails where but fen fowls are kept, some of the co-operating causes will be found to be in active operation, inviting and a idling the specific cance to make the attack. If the fowl honses and yards are swall, damp, and poorly venti. lated, it is reasonable to suprose that the emanations might be sufficiently concentraterl to arlinit of the poison being generated.

Where a larye number are kept together and they are cumpt from the disease, it is becanse the emanations have not been permitted to accumulate and concentrate sufficiently to admit of the poison being formed, or not formerl in suflicient quantity to produce the disease, not having the necessary assistance of aiding causes.

Cholera sometimes prevails where fowls are not regularly housed but seek their roosting places in the open air and elsewhere. On making an examination of the surroundings a satis factory solution of the matter will generally be obtained. Such cases are generally where a larce number of fowls are kept, and many of them during night and in stomy weather are huthled together in small and monitable plarus: and some of those re 
sorts no doubt are in such a conlition as to lavor the produc tion of the cholera poison.

The infectious miasma emanating from fowls that have the cholera rarely communicates the disease except to fowls that are in the immediale vicinity, for concentration of the miasma is gerierally necessas y.

There is no question comnected with the subject of Chicken Cholera that is of more importance for the poultry breeder to understand, than that which relates to its cause. The disease loes not counc hy chance-it is the natural result of certain irregularities. This is a thinking, inventive age, and when we are able to trace this ciscace to its scurce, then we may expect to be able to prevent, and to stay its ravages. But it is important that our ideas of its causc be clear, lefinite, and correct. We repeat that a knowledge of the cause of this disease is highly important in a practical view, because if measures are employerl with a view to prerent, or to exterminate the disease, they must be based on the correct theosy of its cause in arder to be effectual.

The various phenomena of the disease are of such a character that we must recognize them as having a specific origin; and in order to be successful in our eflorts to prevent the disease, we must go a step further-we must understand what that specific cause is, and what are the conditions necessary to its production.

The theory that has been wresenter in the preceding remarks is believed to be founded on fact, and that it is in harmony with the observations of those who have noted the workings of the disease, and who have had their attention specially called to this matter. 


\section{The Symptoms of Cholera.}

VHE symptoms of chicken cholera are not well under. C. 10 stood by the people generally, and it is probable that D.(2) some men have that disease "on the brain," so much so that whenever they lose fowls by any unusual disease that they do not understand, to attribute their death to cholera. Many fowls go to their grave (so to speak) by other diseases and chclera is blamed for sending them there.

Every one who keeps fowls should be able to distinguish cholera from other diseases, for without such knowledge intel. ligent treatment is impossible.

Some of the prominent external symptoms will be given, and so far as known the morbid condition of the internal organs, and the pathological character of the diseaso.

\section{I.-THE EXTERNAL SYMPTOMS.}

The fowl has a dejected, sleepy and drooping appearance and does not plume itself, is very thirsty, has a slow stalking gait, and gaps often. Sometimes the fowl staggers and falls down from great weakness. The comb and wattles lose their natural color, generally turning pale, but sometimes they are dark. There is diarrhea with greenish discharge, or like sulphur an $\mathcal{A}$ water, afterwards it becomes thin and frothy. Prostration comes on, the crop fills with mucus and wind, and at last the food is not digested, breathing is heavy an.l fast, the eyes close and in a few hours the fowl dies 
When fowls die it is very easy to say that they dicd oj cho? era and so let, it go; but if the symptoms were not substantially as given above, an autopsy would show that it was not that disease.

\section{II.-THE MORBID CONDITION OF THE INTERNAL ORGANS.}

On dissecting a fowl that has died of choler:t, the gizzard will be found to be filled with dried up food, or sometimes with a greenish matter, and the crop will be inflaterl with sour mucus and food. The liver will be much enlargerl and flabby, and so tender that it will easily mash in the hand; and it is generally much congested. The crop and intestines are much inflamed, and the latter are filled with a greenish matter. The heart is sometimes enlarged.

\section{III.THE PATHOLOGICAL CHARACTER OF TIE DISEASE.}

The disease affects the liver in such a way that it ceases to perform its function in secreting healthy bile, and as a consequence digestion ceases. There appears to be an excess of acid in the crop, gizzard and bowels, but we cannot tell exactly what produces it. Some of it may be the consequence of indigestion, and it is quite probable that the liver secretes what is known as vitiaterl bile, which often contains a large amount of acid.

The symptoms and the morbid condition of the internal organs are of such a nature as to suggest the probability that a virulent poison is the cause of the disease, but just how it acts on the system to produce such results is unknown. The toxical effect may be sufficient to canse congestion of the portal 
veins, and a suspension or perversion, of the hepatic lunction. When such a condition of the system becomes established, there might be a tendency to proluce fulse hypertrophy of the liver-that is, an culdurement of that orsan and a morlid condition of its structure.

Tannersays: "Hepatic circulation is affecterl by so many different agencies that congestion, or undue accumulation of blood in the vessels of the liver, is a morbid state frequently met with. Moreover, it is the initiative step in many of the structural and functional diseases of this organ."

Softening and enlargement of the liver, as well as conges tion of that organ are some of the prominent post mortem evidences of chicken cholera. 


\section{The Prevention of Cholera}

-O LL of the preventive measures that I have to recom mend are based on the theory of its cause, and they Sxis will be presented under three heads.

\section{I.-PREVENT THE CO OPERATIVE CAUSES.}

The greatest men of our age, or of any other age, would never have risen to greatness and to the performance of wonderful deeds, had they not been surrounded by lavorable and aiding influences. This statement is made to illustrate the views that I entertain on the juestion of our ability to prevent chicken cholera.

Some suppose that this disease is like the wind that blow. eth, that we may see its destructive effects, but that we cannot tell whlunce it cometh, or whither it goeth. But it has already been shown that this is not the case. This disease has a specific cause, but certain conditions and influences are generally necessary to act as co operating causes. These conditions and causes are under our control, and we can permit them, or prevent them just as we choose; and it will be shown in the proper place that these remarks will also apply to the specific cause.

It must he understond that prementime the conperating sauscs, simply means that fowls shall have that nanagement. and care that their circumstances and nature requires. 
Teep close to the requirements of nature, and there will be no cholera.

During hot weather fowls should be provided with some suitable place where they can resort for shade, for the extreme heat of the summer has a debilitating effect upon them; and it stimulates the liver to excessive action. In cool weather they should have warm and comfortable roums. Fowls should be kept free from lice, for a lousy hen is already diseased and in just the condition to invite an attack of cholera.

The practice of keeping fowls too closely confined is very weakening. Exercise and fresh air are the conditions that are necessary for good iligestion and active circulation of the blood.

Their tool should be wholesome and in sufficient variety, such as wheat, oats, fresh meat, cooked vegetables, warm mush, and but very little dry corn, especially in hot weather. The fulndation of disease is often laid in over-feeding. Fowls that are over-fit, or lean, are unhealthy, and the best condi. tion to keep them in is in "good working trim." They should have a plenty of pure fresh water, clean gravel, ground bone, and an anti-acid; the latter may be furnished to fowls by giving them charcoal, old plaster, and crumb s of lime from a slacking box.

It is not necessary to continue these remarks further, but it must be understool that all causes of debility and ill health must be prevented, and that fowls hould have such care and management as their nature requires. When fowls are fledg. ing, and moulting, as well as during hot weather, and at many other times, they neel extra care. At such times they should have tonics, and aids to digestion The "Donglass Mixture" is one of the best tonics known, and it is also a stimulant to the liser. Three or four days in each week put one ounce of this mixture into every gallon of water the fowls drink, or it 
may be mixed in their feed. The mixture is made as follows: Copperas one pound, dissolve in two gallons of warm water, then stir in one ounce of Oil of Vitriol and jug for use. The "Chicken Powder" is made as follows: Copperas, Cayenne pepper, Sulphur and Resin, of each four ounces, pulverize and mix in their feed three or four times each week. Dose, two spoonfuls for each dozen fowls.

The above remedies are of great value and all wishing to prevent the cholera will do well to use them freely; not as a specific for that disease, but as tending to prevent or modify many of the aiding causes. They are valuable remedies because they place the fowls in that condition where their resisting powers will be increased, and consfquently less likely to take the disease.

\section{PREVENT THE FORMATION OF THE SPECIAL CAUSE.}

To avoid a repetition the reader is referred to the remarks on the "specific cause" of this dicease, but it may be proper to say that the disease is of such a character that we are justified in concluding that it originates from a specific cause. This conclusion is a fair deduction from the principles of medical science. The specific cause that I have suggested is entirely adequate to produce the disease, and my theory can be supported by more evidence than can be brought to support any hypothesis whatever.

The questions that are now before us are of considerable importance. Can we nrevent the formation of the specific cause of chicken cholera? If so, how can it be done? The first question I answer in the affirmative; the second is answered by saying: Prevent the conditions that are necessary to its production; and this idea will he further illnstrated by the following plan. 
If the fowls must be confined, their yards should be on high and dry grrund, with a good exposure to sun and air; and they must be sufficiently large and be kept clean and whole. some. It is necessary to often strew fresh lime over the ground and the soil should be turned over occasionally.

Beware of throwing feed on the ground, especially if it (the ground) has been fouled by a flock of hens The better plan is to feed in clean boxes or troughs. If the grain is left laying around on the ground it will soon become sour and unwholesome. These remarks properly belong to the preceding subiect, but as they were omitted, they are inserted here.

The fowl house must be so arranged, and have such fixtures and such management that it will not furnish the conditions necessary to the production of the poison.

After having read the remarks on the conditions required to produce the poison, most persons will know how to proceed to prevent its formation, but we will give a few directions.

The fowl house should be on high and dry ground, and properly arranged for the comfort of the fowls. It should front the south and be provided with windows for the admission of light and the warm rays of the sun. Beware of hav ing the house dark and damp, for evil lurks in such places.

It must be room! and completely ventilated. A number of openings near the floor for the admission of fresh air are necessary, and also in or near the roof for the escape of gases and the emanations from the bodies of the fowls. The doors and windows should often be left open, fresh air must be admitted to dilute and disperse the emanations. The house and yards should not only be rooiny, out be kept clean and wholesome.

It will be necessary occasionally to use disinfectants, and the reacler is referrerl to the remarks which will be malle on that subject in the appropriate place.

The mumber of imnls licpt stwerld be proportioned to the sior o! 
their house and the extent of their ranye. Here is where many have made a mistake. The consequence of overcrowding is the production of a large amount 'of emanations from the bodies of the fowls, and when sufficiently concentra. ted the specific poison will be generated. A roosting room eight feet square may be large enough for twenty-five fowls, but it would be unsafe for fifty to be housed in a room of that size. But it must be understood that the term "over-crowd. ing" is not to be exclusively applied to the number of fowls in the roosting house, for it also applies to the number kept to. gether on a certain extent of range. The size of the flock should be proportioned to the extent of range and other conveniences, but there is a limit beyond which it is unsafe to go. But it is safe to say that large numbers of fowls may be kept by observing in due proportion the conditions of success with a few. They may be kept in large flocks if they are skillfully managed and have extended conveniences, but the better plan is to divide them into flocks of fifty or less.

Remarks on this subject are closed by saying that space, ventilation, cleanliness and disinfiction are the conditions of suc. cess in attempting to prevent the formation of the specific cause of cholera. And if these conditions are complied with to the extent that nature requires, it will be as impossible for the cholera poison to be generated, as it is for the cause of intermittent fever to be produced in a non-malarious locality.

It forms no part of my plan to make an extended argument, or to give my own experience in order to prove or to illustrate my views.

In a work of this size every idea must be presented briefly, and the reader is cautioned to not be led into the error of thinking that because some things have been presented in so few words that they are of but little importance.

Every suggestion that has been made in reference to pre- 
venting the special cause, should be considered as of great importance though they may be but briefly referred to.

In concluding our remarks on the subject of preventing cholera, it is proper to state that by preventing the co operating causes, it is almost certain that the disease will be prevented, and that by preventing the formation of the spccial cause, the disease will be impossible.

And I wish to say further, that if the aiding causes are not all prevented, there can be no cholera unless the specific cause is produced. The aiding causes will produce other diseases, but they are not capable of producing cholera.

There will be instances where, from lack of judgment or persevering effort, the specific cause will be produced. The plan to adopt in such case will be found under the next head. It will consist of a summary of the preceding directions, and such additional remedies as may be necessary to prevent the disease.

\section{DIRECTIONS FOR PREVENTING THE CHOLERA.}

1. Remove the "co operating causes."

2. Give toni's, liver stimulants, and aids to digestion. To accomplish these objects give the "Douglass Mixture" and the "Chicken Powder" freely.

3. Give the fowls more space. This may be accomplished by diminishing the number of fowls, or by increasing the area of their range and of their houses.

4. The poultry house should be thoroughly ventilated and be kept clean and dry.

5. The buildings, yards, and places of resort should be thor. oughly disinfected.

6 Give the fowls a "preventive" - an agent that will destroy or render inert, the poison they have taken into their system. 
There is no agent known that will accomplish this as quickly, and so effectually, as Coal Oil. I have an experience with coal oil that gives me an assurance that it is a valuable remedy, and a reliable preventive.

The preceding directions, and the coal oil, is all that I wish to recommend as "preventives." If the latter is faithfully used nothing else will be needed. I could have easily collected from various sources a score or two of receipts and made a great parade of them, but it would have only tended to bewilder and mislead the reader, for in most cases such receipts are unreliable. The coal oil should be given three or four times a week, as follows: Take a feeding of corn or wheat and let it soak in the oil a few hours, then feed it to the fowls. 


\section{Extermination of Cholera.}

N 1 HiS subject will be presented under the heads of exterminating the disease from the premises, and the treatment of the discase.

\section{HOW TO EXTERMINATE THE DISEASE FROM THE PREMISES.}

1. Read the remarks under "Prevention of Cholera," and all of the directions that refer to the "co operating causes," "tonics," "liver stimulants," "aids to digestion," "space" and "ventilation," must be complied with.

2. Bury the dead and hurry up the dying, so as to get them out of the way; and confine the affected by themselves. The disease is not very contagious, but it is sufficiently so as to make a separation necessary.

3. As has been stated, put the whole flock, sick and well, under treatment; giving them nut only the "Douglass Mixture" and "Chicken Powder," but coal oil should be given freely.

4. Use disinfecting agents that will remove the poison from the buildings and the yards. There are a number of such agents, and some of them are probably effective by destroying the specific poison by chemical action.

The fumes of burning coal tar and sulphur are of considerable importance in purifying an infected building. A mixture of tar and sulphur should be poured into a kettle that has 
been filled with fire and corn cobs. Place this in the building and close the doors and windows. It is important that the building be completely filled with the smoke for one or two hours.

Fresh lime is of great value and should be freely used Whitewash the building, and strew dry lime over the floors and yards.

Perhaps for general use, carbolic acid is as good a disinfec. tant as can be obtained. It is convenient to use and is effec tive. A saturated solution of the acid should be sprinkled around in the building and in the yards.

One of the most reliable disinfecting agencies known to experienced investigators, is dry heat. There are many instances where medical men have had recourse to this agency for the purpose of purifying infected buildings, suzh as pest-houses, hospitals, \&c. As it will occasionally be convenient to resort to this method of purifying an infected fowl house, I will give the necessary directions. Build a hot fire in the house and close the doors and windows so as to retain the heat. Continue the heating for two hours, and until the room is about as hot as an oven. A temperature from $200^{\circ}$ to $260^{\circ}$ Fah., will destroy the specific cause of chicken cholera.

A number of the disinfectants mentioned should be user, and $r \in$ peated daily, the coal oil given freely and cholera will be "exterminated."

\section{HOW TO TREAT THE DISEASE.}

1. Confine the affected fowls by themselves and keep their rooms disinfected with carbolic acid.

2. Give no food except warm mush and soaked bread. The crop and bowels are in such a deranged condition that hard feed will aggravate the disease and prevent a cure. 
3. Give coul oil every day to counteract the poison. The best way to administer it is to pour it down the fowl with a spoon. I have known severe cases of the disease to be cured by giving a teaspoonful of the oil at one dose

4. Give five grains of bi-carbonate of soda twice a day to neutralize the excess of acid.

5. The disease is of such a nature as to indicate the necessity of a purgative anci alterative remedy to unload the congested blood ressels of the liver, and to cause that organ to perform its double office of separating impurities from the venous blood and of secreting hile necessary to digestion. The irritation of the intestinal canal should be reduced, and the distressing tenesmus relieved.

To meet these indications the "Cholera Pills" should be used. They are made as follows: Blue mass 60 grains, pulverized champhor gum 25 grains, cayenne pepper 30 grains, tincture of opium 60 drops. Mix and make into 16 pills. Give one of these pills every five hours until they act freely, after that one a day, for two or three days, will be sufficient.

Opium is the only astringent remedy that should be given to fowls that have the cholera. After discontinuing the use of the pills, the "Chicken Powler and Donglass Mixture" should be used every day.

Nany seem to think that the important thing to do, in order to cure chicken cholera, is to administer powerful astringents to check the diarrhea, but that is only doctoring the symptons, not the disease, and such treatment will generally be injurious and often prevent recovery. A more rational treatment is to neutralize the excess of acil, counteract the poison, unload the congested blood vessels of the liver, correct the wrong action of that organ so that it will secrete healthy bile which is necesatry to rligestion, and allay the irritation of the cron and bow els. After the "Cholera Pills" have had a sufficient action, if 
the diarrhea continues, give a teaspoonful of castor oil, or enough to act freely, and then give ten to twenty drops of tincture of opium three or four times a day, or as often as may be necessary.

Fowls sometimes die from apoplexy, from heart disease, from excessive heat, from internal tumors, and from many other causes, and such deaths are often attributed to cholera. These remarks are marle because I do not wish the above remedies to sink into disrepute for not preventing or curing diseases $\mathrm{for}_{\mathrm{r}}$ which they are not allapted and not recommended. To be effectual in curing cholera, the remedies must be employed in the early stage of the disease. 


\section{The Conclusion.}

(ง) 19 E have taken the position that the chclera poison is 2. (3 produced from the concentrated emanations from the (9) (2) bodies of fowls, but I wish to add a remark or two so that I may be clearly understood. When fowls are in a low unhealthy condition it is quite probable that the cholera poison will be produced more readily than when fowls are healthy and free from the influences of all causes of ill-health.

The directions for treating the sick fowls are brief. There will be no necessity for employing any remedies except those which have been presented, for it is believed that they are based on the nature of the disease, and on the correct theory of its cause. The treatment is therefore based on rational and scientific principles, and I would advise the "Chicken Powder," the "Douglass Mixture," and the Alkali to be given every day to the sick and well, during cholera times. Also, the coal oil should be faithfully employed. The sick must in all cases be confined in a comfortable and wholesome room, and when pros tration comes on they should have a stimulant, such as brancly or whisky, in teaspoonful doses:

I do not propose to cure every case of cholera. I claim to be able to prevent it, and to exterminate it. Ind it is also clamed that the alowe treatment will cure most cuses, if they are taken in time. It is further claimed, that if tow have the management and care that I have insisted on, they will not 
only be free from cholera, but will be more healthy, will lay more eggs; and be more profitable.

If this little work shall meet with the favor of my brother poulterers, and if it shall tend to advance the poultry interest by bringing a feeling of security from cholera, my desires will be attained. 


\title{
W. H. Todd's Viewss.
}

\begin{abstract}
จ. (4. R. W. H. TODD has kindly favored me with some of c. 5 his views on the subject of Chicken Cholera, and al(6) though they were not designed for the public, yet as his words will have a weight that I cannot hope my own will have, I take pleasure in having the liberty to give to the public, through this channel, the following extracts from his letters:
\end{abstract}

"I know but little about cholera from practical experience. I believe half that is called cholera is something else. I think we err in housing too close and not giving exercise enough, and in exhausting the digestive organs by feeding too much, especi. ally to mature fowls. I am now of the opinion that we can stay and prevent most contagious diseases by understanding fowls' needs, and by proper management. I don't think any of my birds ever had the disease; but once or twice they had a touch of something very near it. I checked it by using daily carbolic acid disinfectants in the houses, and by getting all the fowls out, and building hot fires in the houses after closing them up tight, and "purifying by fire" daily for an hour. I believe in a dry dirt floor four to six inches deep, and in keeping the houses clean, and often whitewashing them as a pre. ventive.

I have dissected fow is that have died suddenly with the symptoms of cholera, and found the disease affecterl the digestive or. 
gans and liver, the latter, in most cases, being as tender and easily broken as jelly, more or less enlarged, and much conges. ted. The liver appeared to be torpia; bile not being discharged sufficiently to aid digestion, and there seemed to be too much acid in the bowels and gizzard, both being filled with greenish matter. This being the case, powerful aperient and alterative remedies were indicated for a cure. I tried Blue Mass and Calomel whenever I saw a hen looking pale, and re. fusing to eat, or moping about. I give one or two grain doses of calomel twice a day, or twice as much blue mass mixed with about the same quantity of cayenue pepper, and one-half the quantity of camphor gum with a little flour and castor oil for pilling. These remedies I have used with excellent results

A.s I have not had much experience with cholera I cannot give much information about it, but I believe I can handle it, and prevent it."

W. H. TODD.

Vermillion, 0 .

The cause of cholera is not referred to in Mr. Todd's letters, and $I$ have no definite information as to what his views are on that subject, but from his remarks about "purifying the fowl houses with fire," I am led to infer that his views do not differ much, if any at all, from the theory that has been presented in this work. Fearing the cholera had made an attack on his lusty Cochins and Brahmas, he goes to battle; and disinfcctants and hot fircs were his weapons. Those powerful agents were employed to accomplish a special purpose; and that purpose must have been the destroying, or rendering inert, an invisible poison which he supposed was present, and which was the canse of the disease that he dreaded. I can easily believe that Mr. Todd has correct ideas as to the cause of cholera, for it appears that his fowls have had such management, and have been so faithfully protected by his chosen weapons, that only 
"once or twice have they been touchel" with anything that re. sembled cholera. That is a good showing, and what has been done by ore, can be done by others. If the measures recom. mended in this work are employed by poultry breeders and farmers intelligently, faithfully, and perseveringly, cholera will soon be exterminated from the land. 


\section{Poultry Journals.}

d) HERE was an unintentional omission in not giving due C) credit to the Poultry Journals for many valuable ideas (O). that have been of service to me in preparing this work, and I now hasten to do them justice.

We would urge upon all Poultry Breeders, and upon farmers and others who raise fowls, the importance of taking a taking a Poultry Journal. This work will go into the hands of many who will be glad to take a journal of that kind, and for their benefit, the following list of Poultry Journals is compiled:

The Poultry Nation, W. H. Todd, editor, Vermillion, Ohio, monthly, 50 cts per year; The Poultry Record, C. W. Heaton, editor, Farmington, Ills., monthly, $\$ 1$ per year ; The Swineand Foultry Journal, Ward and Darrah, editors, Cedar Rapids, Ia, monthly, \$1.25 per year; The Poultry Argus, Miller and Clinton, editors, Polo. Ills., monthly, \$1 per year; Northuestern Pouitry Journal, T. T. Bacheller, editor, Minneapolis, Minn., monthly, $\$ 1$ per year; Poultry World, H. H. Stoddard, editor, Hartford, Conn, \$1 25 per year, monthly; National Poultry Journal, C. C. Carpenter, editor, Minneapolis, Minn., monthly, $\$ 1$ per year; The Fanciers' Journal, Jos. M. Wade, editor, weekly, Philade!phia, Pa., $\$ 250$ per year.

Make a selection of the one you want and send direct to the Editor. They are all valuable journals, and ably conducted. 


\section{Burbank Poultry Yards.}

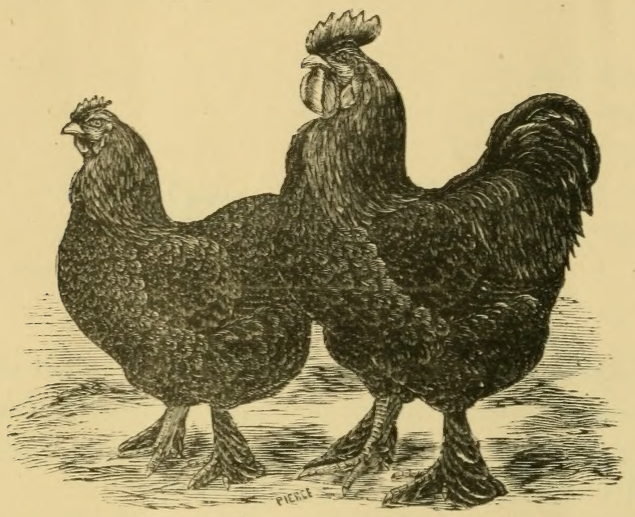

BLACK COCHINS.

\section{A. J. HILL, PROPRIETOR,}

ALSO, AUTHOR OF THE

\section{"CHOLERA PREVENTIVE AND EXTERMMATOR."}

I am breeding a few choice fowls of the following varieties:

Buff Cochins, Jones of Green, \& Todd strains. Black Cochins, Phillander Williams'strain. Brown Leghorns, Todil Stock.

First-Class Fow/s, and Egges for Hatching shipped to any point. and warranted to arrive in good condition and to be as represented. Any one interested in fine fowls, and wishing to visit my yards are cordially invited. I will not be hard to tind, for,

As you go east from Burbank, A haif a mile, may be,

Onr coops on wheers, and painted yards. You cannot fail to see.

AGFiN'TS W ANTF:D for the Cholern Preventive and Exterminator. Liberal terms to all Poultry Breeders who wish to obtain copies of this book in large quantities for their customers. Single copies sent to any address for 50 cents. Wholesale price given on application. Send stamp for price list of Fowls and Eggs. Address, A.J. HILI, BurbaNk, Wayne Co., OHio. 



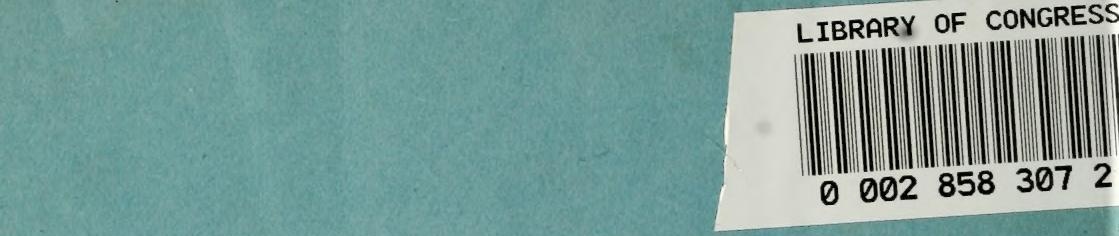
(

$$
2
$$

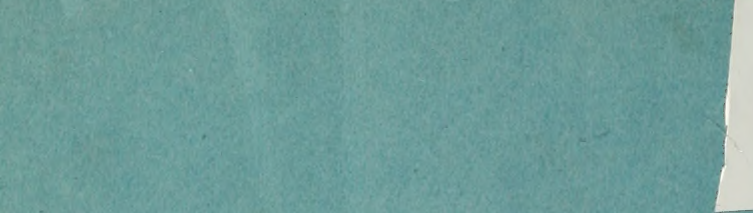

